\title{
Redox tuning of cytochrome b562 through facile metal porphyrin substitution
}

Della Pia, Eduardo Antonio ; Chi, Qijin; Elliott, Martin; Macdonald, J. Emyr; Ulstrup, Jens; Jones, D. Dafydd

\section{Published in:}

Chemical Communications

Link to article, DOI:

$10.1039 / \mathrm{c} 2 \mathrm{cc} 34302 \mathrm{a}$

Publication date:

2012

Document Version

Publisher's PDF, also known as Version of record

Link back to DTU Orbit

Citation (APA):

Della Pia, E. A., Chi, Q., Elliott, M., Macdonald, J. E., Ulstrup, J., \& Jones, D. D. (2012). Redox tuning of cytochrome $b_{\text {, }}$ through facile metal porphyrin substitution. Chemical Communications, 48(86), 10624-10626. https://doi.org $562.1039 / \mathrm{c} 2 \mathrm{cc} 34302 \mathrm{a}$

\section{General rights}

Copyright and moral rights for the publications made accessible in the public portal are retained by the authors and/or other copyright owners and it is a condition of accessing publications that users recognise and abide by the legal requirements associated with these rights.

- Users may download and print one copy of any publication from the public portal for the purpose of private study or research.

- You may not further distribute the material or use it for any profit-making activity or commercial gain

- You may freely distribute the URL identifying the publication in the public portal 


\section{Redox tuning of cytochrome $\boldsymbol{b}_{\mathbf{5 6 2}}$ through facile metal porphyrin substitution $\dagger$}

\author{
Eduardo Antonio Della Pia, ${ }^{a c}$ Qijin Chi, ${ }^{b}$ Martin Elliott, ${ }^{c}$ J. Emyr Macdonald, ${ }^{c}$ \\ Jens Ulstrup ${ }^{b}$ and D. Dafydd Jones $* a$
}

Received 15th June 2012, Accepted 7th September 2012

DOI: $10.1039 / \mathrm{c} 2 \mathrm{cc} 34302 \mathrm{a}$

The biologically and nanotechnologically important heme protein cytochrome $b_{\mathbf{5 6 2}}$ was reconstructed with zinc and copper porphyrins, leading to significant changes in the spectral, redox and electron transfer properties. The $\mathrm{Cu}$ form shifts the redox potential by $+300 \mathrm{mV}$ and exhibits high electron transfer, while the $\mathrm{Zn}$ form is redox inert.

Metalloproteins comprise one of the most abundant protein groups in nature; between a third to half of all natural proteins bind metal ions. ${ }^{1}$ This class of proteins is of particular importance as they are involved in a variety of key biological processes ${ }^{2}$ and, over the past decade, significant progress has been made for their integration in hybrid bio-electronic devices. ${ }^{3}$ The metal ion plays a key role defining the activity of a protein either indirectly through determining the conformation or directly through involvement in the mechanism of function. A variety of different metal ions are utilised in nature, among which the most important ones are $\mathrm{Zn}^{2+}, \mathrm{Fe}^{2+/ 3+}$ and $\mathrm{Cu}^{+/ 2+} \cdot \mathrm{Zn}^{2+}$ is an important structural metal but also contributes to activating water for hydrolysis reactions. ${ }^{4}$ Both $\mathrm{Fe}$ and $\mathrm{Cu}$ are largely involved in electron transfer processes. ${ }^{5,6} \mathrm{Fe}$ in the form of heme (iron protoporphyrin IX) is particularly important as it plays central roles in photosynthesis, respiration, transport and catalysis. Natural heme proteins show a wide range of redox potentials $(650 \mathrm{mV})$ tuned mainly by interactions with the protein scaffold and the axial ligands. ${ }^{5}$ As well as being involved in electron transfer pathways in photosynthetic chains, several $\mathrm{Cu}$-containing proteins facilitate electron flow between electron donors and dioxygen. ${ }^{6}$

The ability of individual metalloprotein molecules to selfassemble and modulate the properties of the bound metal ion make them attractive for use as active single molecule nanoscale components and materials. Furthermore, the move from bulk to single molecule metalloprotein approaches and analysis

${ }^{a}$ School of Biosciences, Main Building, Cardiff University,

CardiffCF10 3AT, UK. E-mail: jonesdd@cardiff.ac.uk

${ }^{b}$ Department of Chemistry and NanoDTU, Technical University of Denmark,DK-2800 Lyngby,Denmark.E-mail: cq@kemi.dtu.dk

'School of Physics and Astronomy, Queens' Building,

Cardiff University, Cardiff CF24 $3 A A, U K$

$\dagger$ Electronic supplementary information (ESI) available: Materials and methods, SDS-PAGE analysis, spectrophotometric titration of D50C apo-cyt $b_{562}$ with Zn-PP and Cu-PP, UV-Vis and Far UV circular dichroism spectra of Zn-PP and Cu-PP cyt $b_{562}$, cyclic voltammetry of the Cu-PP, Laviron's plot. See DOI: 10.1039/c2cc34302a will ultimately lead to new fundamental functional and mechanistic insights. Simple, robust redox active proteins are particularly attractive as single molecule devices as they exhibit transistor-like behaviour. ${ }^{7}$ Gating is achieved via electrochemical and biochemical events that alter the redox potential which in turns modulates electron transfer or current flow characteristics. One such protein that could be considered ideal for such applications is cytochrome $b_{562}$ (cyt $b_{562}$ ). Cyt $b_{562}$ is a small redox-active protein found in $E$. coli that has a four helical bundle structure that coordinates to the heme iron through the axial ligands Methionine 7 (Met7) and Histidine 102 (His102) (Fig. 1(a)). ${ }^{8}$ Cyt $b_{562}$ has proved particularly useful for the fundamental understanding of the electron transfer process in proteins and for the development of new bioelectronics devices. ${ }^{7}$ It can also be linked to other proteins so the functional centres are coupled. ${ }^{9}$

Crucially, we have recently shown that cyt $b_{562}$ can be designed to bind non-biological surfaces such as gold in defined orientations through the introduction of a cysteine amino acid at specific points in the protein structure. ${ }^{7}$ The introduction of a thiol group
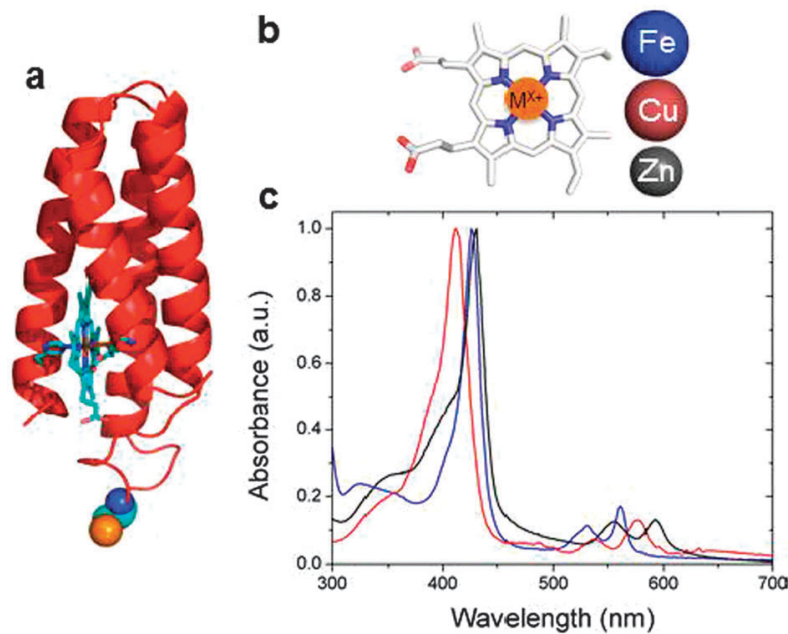

Fig. 1 (a) Structure of holo-cyt $b_{562}$ (PDB, 256B). The cyt $b_{562}$ ribbon structure is coloured red, the heme group is shown in light blue and the amino acid targeted for mutation is highlighted as spheres. (b) Chemical structure of (blue) iron, (red) copper and (black) zinc protoporphyrin IX. (c) Normalized UV-Vis spectra of $20 \mu \mathrm{M}$ D50C cyt $b_{562}$ reconstructed with (blue) $20 \mu \mathrm{M}$ heme, (red) $20 \mu \mathrm{M} \mathrm{Cu-PP}$ and (black) $20 \mu \mathrm{M} \mathrm{Zn-PP} \mathrm{in}$ $10 \mathrm{mM}$ phosphate buffer $\mathrm{pH} 6.2$. 
by exchanging an aspartate for cysteine at residue 50 (D50C) has proved particularly useful. ${ }^{7}$ Using engineered proteins in conjunction with single molecule STM studies has allowed us to demonstrate that cyt $b_{562}$ is highly conductive with conductance being electrochemically gated. ${ }^{10}$ The ability to tune the redox potentials and add different conducting centres would thus expand the application of cyt $b_{562}$ and improve our fundamental understanding of metal-protein interactions. There has been some success in varying the redox potential of cyt $b_{562}$ through conventional protein mutagenesis by tuning the protein's interactions with the heme group. ${ }^{5,11}$ However, this approach has generally resulted in lowering the redox potential and has been restricted to sampling the $\mathrm{Fe}^{2+} / \mathrm{Fe}^{3+}$ centre. ${ }^{5,11}$ Also, as these engineered proteins do not bind directly to metallic electrodes, direct electron transfer cannot be realised or is relatively slow.

In the present study we combine two approaches to measure and modulate the redox properties of cyt $b_{562}$; utilisation of the D50C variant to facilitate defined and direct binding to a single gold electrode, ${ }^{7}$ which in turn allows direct investigation of the effect of metal ion replacement through facile co-factor exchange. As $b$-type cytochromes bind heme non-covalently via axial ligands, heme can be easily removed and replaced by other porphyrins with the metal centre substituted with redox active copper protoporphyrin IX (Cu-PP) and photoactivatable zinc protoporphyrin IX (Zn-PP) (Fig. 1(b)). The use of the cyt $b_{562} \mathrm{D} 50 \mathrm{C}$ variant will allow cyclic voltammetric methods based on well defined atomically planar single-crystal electrodes to be used.

Cyt $b_{562}$ was generated to high purity and homogeneity (Fig. S1, ESI $\dagger$ ). Binding of Zn-PP and Cu-PP to cyt $b_{562}$ D50C monitored by UV-Vis spectroscopy resulted in markedly different spectral characteristics compared to the heme bound form (Fig. 1(c)). A significant red shift $(\sim 36 \mathrm{~nm})$ and a narrower bandwidth were observed for both the Zn-PP and $\mathrm{Cu}-\mathrm{PP}$ Soret Band on addition to apo-cyt $b_{562}$, which can be interpreted as incorporation of the PPs into the protein (Fig. S2 and S3, ESI $\dagger$ ). Far UV circular dichroism (CD) spectroscopy further indicates that $\mathrm{Cu}-\mathrm{PP}$ and $\mathrm{Zn}-\mathrm{PP}$ bind in a similar fashion to heme (Fig. S4, ESI $\dagger$ ). Apo-cyt $b_{562}$ is only partially folded and heme binding within the active pocket of the protein results in a structural transition towards stable formation of the helical bundle structure (Fig. 1(a)). ${ }^{8}$ The increase in helical signatures (troughs at 208 and $222 \mathrm{~nm}$ ) in the CD spectra of cyt $b_{562}$ D50C associated with heme binding are observed in the presence of either $\mathrm{Cu}-\mathrm{PP}$ or $\mathrm{Zn}-\mathrm{PP}$. The virtually identical CD spectra of cyt $b_{562}$ reconstituted with heme, $\mathrm{Cu}-\mathrm{PP}$ or Zn-PP further support that the protein scaffold and co-factor binding mode remains intact on metal substitution.

The Soret band in all holo-protein forms was observed together with the $\alpha$ and $\beta$ bands (Fig. 1(c)). Cyt $b_{562}-\mathrm{Zn}$-PP has peaks at $431 \mathrm{~nm}$ (Soret band), $558 \mathrm{~nm}$ ( $\beta$-band) and $592 \mathrm{~nm}$ ( $\alpha$-band) and a broad shoulder at $360 \mathrm{~nm}$. The spectra of the D50C cyt $b_{562}$ reconstructed with Cu-PP shows peaks at $414 \mathrm{~nm}$ (Soret band), $537 \mathrm{~nm}$ ( $\beta$-band) and $579 \mathrm{~nm}$ ( $\alpha$-band) and a shoulder at $350 \mathrm{~nm}$. The holo-cyt $b_{562}$ (with heme bound) shows an intense Soret band at $427 \mathrm{~nm} .{ }^{9,12}$ Changes in the axial ligand coordination of the cyt $b_{562}$ 's Met7 and His 102 amino acids to the $\mathrm{Zn}-\mathrm{PP}$ and $\mathrm{Cu}-\mathrm{PP}$ might account for the shift of the Soret band towards higher ( $\mathrm{Zn}-\mathrm{PP})$ and lower $(\mathrm{Cu}-\mathrm{PP})$ wavelengths in comparison to the heme-cyt $b_{562}$. In particular the Soret peak of the cyt $b_{562}-\mathrm{Cu}-\mathrm{PP}$ at $414 \mathrm{~nm}$ suggests a 5 -coordinated $\mathrm{Cu}-\mathrm{PP}$ complex ${ }^{13}$ and the ratio $\varepsilon_{\alpha} / \varepsilon_{\beta}>1$ is evidence of coordination of the $\mathrm{Cu}-\mathrm{PP}$ to a nitrogen acceptor. ${ }^{14}$

An established spectroscopic approach ${ }^{15}$ was used to measure the affinity of cyt $b_{562}\left(K_{\mathrm{d}}\right)$ for each of the PPs by measuring the increase in Soret band absorbance on addition of PP. Both the Cu-PP and Zn-PP titrations indicated that approximately one molecule of apo-protein binds with one PP molecule (Fig. S5 and S6, ESI $\dagger$ ). The $K_{\mathrm{d}}$ values of $\mathrm{Zn}-\mathrm{PP}$ and $\mathrm{Cu}-\mathrm{PP}$ for cyt $b_{562}$ were $500 \pm 80 \mathrm{nM}$ and $100 \pm 30 \mathrm{nM}$, respectively. These values are at least one order of magnitude higher than the $K_{\mathrm{d}}$ values calculated for the oxidised hemeapo-cyt $b_{562}$ complex, ${ }^{9,12}$ indicating that the affinity for $\mathrm{Cu}-\mathrm{PP}$ and $\mathrm{Zn}-\mathrm{PP}$ is lower but still relatively high in biological terms.

The redox properties of high purity cyt $b_{562}$ reconstructed with the redox inactive $\mathrm{Zn}-\mathrm{PP}$ or redox active $\mathrm{Cu}-\mathrm{PP}$ (Fig. S1, ESI $\dagger$ ) were investigated by cyclic voltammetry. Holo-protein was adsorbed in a defined manner onto the $\mathrm{Au}(111)$ surface via the thiol group introduced at residue $50 .^{7}$ The $\mathrm{Cu}-\mathrm{PP}$ cyt $b_{562}$ displayed stable and reversible electrochemical characteristics in keeping with cycling between the $\mathrm{Cu}^{+}$and $\mathrm{Cu}^{2+}$ states. Direct electron transfer was consistently detected by normal cyclic voltammetry, indicating effective electronic coupling between the $\mathrm{Cu}-\mathrm{PP}$ center and the electrode. Fig. 2(a) shows an example of the reversible cyclic voltammogram recorded for this system. A pair of well-defined redox peaks was observed with a formal redox potential $\left(E^{0 \prime}\right)$ of $205 \pm 5 \mathrm{mV} v s$. SCE. Cathodic and anodic peaks are not completely symmetric, suggesting that the protein does not retain its original conformation or surface orientation upon copper oxidation, or more likely that the coordination of the $\mathrm{Cu}-\mathrm{PP}$ with the protein's active site changes upon its oxidation. It is noticeable that the redox potential is significantly different from that for the $\mathrm{Cu}-\mathrm{PP}$ alone measured in homogeneous solution state $(50 \pm 2 \mathrm{mV} v$. SCE; Fig. S7, ESI $\dagger$ ). This observation is a clear indication that despite not being the cytochrome's native cofactor, the polypeptide scaffold plays a crucial role in the redox chemistry of $\mathrm{Cu}-\mathrm{PP}$ making it a much stronger oxidising agent and might be viewed as a facilitator of electron transfer between the redox center and the electrode. The substitution of the central metal has also a major effect on the redox potential of the cyt $b_{562}$, shifting it positively by $c a .300 \mathrm{mV}$ compared to heme-cyt $b_{562}$. This difference could be rooted in the axial binding of the electronically "soft" His102 (and perhaps Met7) ligand(s) favouring the low oxidation of copper. ${ }^{8}$ This change is significantly
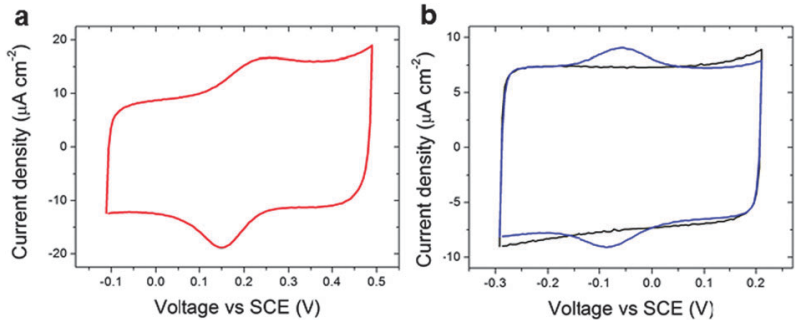

Fig. 2 Cyclic voltammogram of cyt $b_{562}$ D50C reconstructed with (a) Cu-PP (red line) and (b) heme (blue line) or (b) Zn-PP (black line). Protein samples were self-assembled on $\mathrm{Au}(111)$ in $10 \mathrm{mM}$ phosphate buffer $\mathrm{pH}$ 6.2. Scan rate is $1 \mathrm{~V} \mathrm{~s}^{-1}$. 

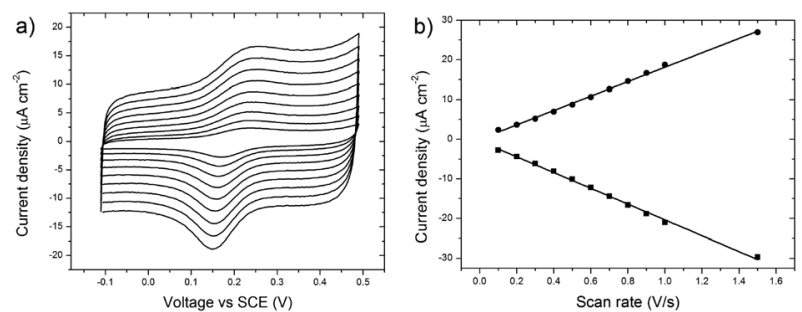

Fig. 3 (a) Cyclic voltammograms at various scan rates (from $0.1 \mathrm{~V} \mathrm{~s}^{-1}$ to $1 \mathrm{~V} \mathrm{~s}^{-1}$ ) of cyt $b_{562} \mathrm{D} 50 \mathrm{C}$ reconstructed with $\mathrm{Cu}-\mathrm{PP}$ and deposited on $\mathrm{Au}(111)$ in $10 \mathrm{mM}$ phosphate buffer $\mathrm{pH}$ 6.2. (b) Corresponding relation between the anodic (circle dots) and cathodic (square dots) peak currents and scan rates. The solid lines are the best linear fits of the experimental data.

larger than has been achieved solely through protein mutagenesis ${ }^{16}$ and shifts the reduction potential to a higher rather than lower value with respect to the heme-bound cyt $b_{562}$ form. ${ }^{11}$

The cathodic and anodic peak currents obtained from cyclic voltammograms depend linearly on the scan rate up to $1.5 \mathrm{~V} \mathrm{~s}^{-1}$ (Fig. 3(a)) suggesting that the electron transfer process is controlled by the surface process (i.e. diffusionless system) and that the proteins are strongly adsorbed onto the electrode. The surface coverage calculated from the slope of the linear fitting of the peak current density against scan rate data $((11.4 \pm 0.8) \times$ $10^{12}$ molecules per $\mathrm{cm}^{2}$ ) indicates an almost full monolayer coverage of the $\mathrm{Au}(111)$ surface with electroactive proteins.

The electron transfer rate constant was evaluated from the observed redox peak current separation variation with the sweep rates in the range $12-22 \mathrm{~V} \mathrm{~s}^{-1}$ according to Laviron's method (Fig. S8, ESI $\dagger$ ). ${ }^{17}$ The rate of electron transfer $\left(14 \pm 2 \mathrm{~s}^{-1}\right)$ obtained is close to the one determined for the heme-cyt $b_{562}\left(44 \mathrm{~s}^{-1}\right){ }^{8}$ Thus, the substitution of $\mathrm{Cu}-\mathrm{PP}$ enhances the oxidizing ability of the cyt $b_{562}$, but retains ET efficiency despite apparent changes in axial ligand coordination. The small difference in ET rate between the Cu-PP and the heme substituted cyt $b_{562}$ could be ascribed to the different polarization of the redox binding pocket that affects the reorganization energy of the proteins, the dominating parameter controlling the ET rate.

No redox activity was measured for the $\mathrm{Zn}$ PP-cyt $b_{562}$ (Fig. 2(b)) demonstrating that the presence of the redox metal centre $(\mathrm{Fe}$ or $\mathrm{Cu})$ is crucial in the protein's electron transfer characteristics. The capacitive background current of the heme-cyt $b_{562}$ is very similar to the one of $\mathrm{Zn}$-PP cyt $b_{562}$ system indicating that the protein's hydrophobic residues are not exposed to the supporting electrolyte. This result, in conjunction with the measured UV-Vis and CD spectra (Fig. 1(c)), supports that the cytochrome maintains its folded tertiary structure when reconstructed with the Zn-PP.

We have shown that the metal centre engineering achieved by protoporphyrin IX replacement can alter the electronic properties of cyt $b_{562}$. Cyt $b_{562}$ is thus a good acceptor and modulator of different metal centre protoporphyrins thus potentially expanding its capacity to sample a range of metal centres and properties. While Zn-PP renders cyt $b_{562}$ electrochemically inert, changing the iron center to copper shifts the redox potential positively by $300 \mathrm{mV}$, while preserving the native holo-protein structure and its electron transfer properties. This change is higher than that currently achieved through traditional protein engineering. The protein itself shifts the redox potential of Cu-PP by $150 \mathrm{mV}$. It is also likely that replacing $\mathrm{Fe}$ with $\mathrm{Cu}$ goes beyond simply changing the redox potential but also the electron transfer mechanism. Engineering the metal centre therefore provides a new route to altering and tuning the redox and electron transfer characteristics of metalloproteins such as cyt $b_{562}$.

This work was supported by the BBSRC (Grant BB/E001084 to D.D.J.) and EPSRC (Grant EP/D076072/1 to J.E.M. and M.E.) in UK and by the Lundbeck Foundation (to Q.C.) and Danish Research Council for Technology and Production Sciences (Contract No. 274-07-0272 to Q.C. and J.U.) in Denmark. E.A.D.P. acknowledges the Cardiff University Richard Whipp Interdisciplinary Research Scholarship for PhD study.

\section{Notes and references}

1 C. L. Dupont, A. Butcher, R. E. Valas, P. E. Bourne and G. Caetano-Anollés, Proc. Natl. Acad. Sci. U. S. A., 2010, 107, 10567-10572.

2 C. R. Robinson, Y. Liu, J. A. Thomson, J. M. Sturtevant and S. G. Sligar, Biochemistry, 1997, 36, 16141-16146.

3 J. Zhang, Q. Chi, A. M. Kuznetsov, A. G. Hansen, H. Wackerbarth, H. E. M. Christensen, J. E. T. Andersen and J. Ulstrup, J. Phys. Chem. B, 2002, 106, 1131-1152; J. Zhang, A. M. Kuznetsov, I. G. Medvedev, Q. Chi, T. Albrecht, P. S. Jensen and J. Ulstrup, Chem. Rev., 2008, 108, 2737-2791.

4 J. E. Coleman, Curr. Opin. Chem. Biol., 1998, 2, 222-234.

5 C. J. Reedy, M. M. Elvekrog and B. R. Gibney, Nucleic Acids Res., 2008, 36, 307A-313A; D. S. Wuttke and H. B. Gray, Curr. Opin. Struct. Biol., 1993, 3, 555-563.

6 H. B. Gray, B. G. Malmström and R. J. Williams, J. Biol. Inorg. Chem., 2000, 5, 551-559; R. K. Szilagyi and E. I. Solomon, Curr. Opin. Chem. Biol., 2002, 6, 250-258.

7 E. A. Della Pia, Q. Chi, D. D. Jones, J. E. Macdonald, J. Ulstrup and M. Elliott, Nano Lett., 2011, 11, 176-182; E. A. Della Pia, M. Elliott, D. D. Jones and J. E. Macdonald, ACS Nano, 2012, 6, 355-361.

8 Y. Feng, S. G. Sligar and A. J. Wand, Nat. Struct. Biol., 1994, 1, 30-35; D. W. Low, M. G. Hill, M. R. Carrasco, S. B. H. Kent and P. Botti, Proc. Natl. Acad. Sci. U. S. A., 2001, 98, 6554-6559.

9 D. D. Jones and P. D. Barker, Angew. Chem., Int. Ed., 2005, 44, 6337-6341; D. D. Jones and P. D. Barker, ChemBioChem, 2004, 5, 964-971; J. A. J. Arpino, H. Czapinska, A. Piasecka, W. R. Edwards, P. Barker, M. J. Gajda, M. Bochtler and D. D. Jones, J. Am. Chem. Soc., 2012, 134, 13632-13640.

10 E. A. Della Pia, Q. Chi, J. E. Macdonald, J. Ulstrup, D. D. Jones and M. Elliott, Nanoscale, accepted.

11 Y. Mie, F. Mizutani, T. Uno, C. Yamada, K. Nishiyama and I. Taniguchi, J. Inorg. Biochem., 2005, 99, 1245-1249; S. L. Springs, S. E. Bass and G. L. McLendon, Biochemistry, 2000, 39, 6075-6082; S. L. Springs, S. E. Bass, G. Bowman, I. Nodelman, C. E. Schutt and G. L. McLendon, Biochemistry, 2002, 41, 4321-4328.

12 E. Itagaki, G. Palmer and L. P. Hager, J. Biol. Chem., 1967, 242 , $2272-2277$.

13 B. Venkatesha, H. Horia, G. Miyazakia, S. Nagatomob, T. Kitagawab and H. Morimoto, J. Inorg. Biochem., 2002, 88, 310-315; P. T. Manoharan, K. Alston and J. M. Rifkind, J. Am. Chem. Soc., 1986, 108, 7095-7100; K. Alston and C. B. Storm, Biochemistry, 1979, 18, 4292-4300.

14 R. E. Sharp, J. R. Diers, D. F. Bocian and P. L. Dutton, J. Am. Chem. Soc., 1998, 120, 7103-7104; H. Anni, J. M. Vanderkooi and L. Mayne, Biochemistry, 1995, 34, 5744-5753.

15 Z. X. Wang, N. R. Kumar and D. K. Srivastava, Anal. Biochem., 1992, 206, 376-381.

16 K. Hamada, P. H. Bethge and F. S. Mathews, J. Mol. Biol., 1995, 247, 947-962; P. D. Barker, J. L. Butler, P. De Oliveira, H. A. O. Hill and N. I. Hunt, Inorg. Chim. Acta, 1996, 252, 71-77; S. L. Springs, S. E. Bass and G. L. McLendon, Biochemistry, 2000, 39, 6075-6082.

17 E. Laviron, J. Electroanal. Chem., 1979, 101, 19-28. 